\title{
Percepções Docentes sobre o Ensino das Relações Étnico-Raciais através das Danças Circulares
}

\author{
Percepciones de profesores en la enseñanza de las relaciones raciales \\ étnicos a través de las danzas circulares
}

\author{
Teaching Perceptions on the Teaching of Ethnic-Racial Relations through \\ Circular Dance
}

\author{
Gisele Maria Rodrigues Machado ${ }^{1}$ \\ Raquel Pereira Quadrado
}

\begin{abstract}
Resumo
Educar para as relações étnico-raciais significa viabilizar para todos(as) os(as) estudantes e professores(as), independentemente de sua etnia, conhecimentos sobre a história e cultura africana e afro-brasileira pois sabemos o quanto a invisibilidade destas interfere na construção de representações sobre o negro no Brasil. Este estudo propõe uma ação pedagógica voltada para o cumprimento da lei 10.639/03 utilizando a metodologia das danças circulares na formação continuada de professores(as) a partir dos valores civilizatórios afro-brasileiros, como: cooperativismo, circularidade, ludicidade, territorialidade, oralidade, religiosidade, ancestralidade, memória e energia vital. As danças circulares proporcionam momentos de cooperação, descontração e introspecção através da prática das danças de diversos povos. De acordo com os dados narrativos de 10 professores(as) que participaram da formação continuada - "Danças Circulares na formação de professores(as) para as relações étnico-raciais", observou-se que as questões sobre racismo, intolerância religiosa e discriminação são as dúvidas e tensões mais frequentes enfrentadas em sala de aula. A utilização das danças circulares para discutir e problematizar estas temáticas foi considerada pelos(as) docentes como uma aprendizagem através do movimento, da oralidade, do acolhimento da roda, ou seja, uma atividade leve e alegre na qual é possível refletir, conhecer, ressignificar e respeitar a diversidade étnico-racial.
\end{abstract}

Palavras-chave: formação continuada de professores(as); racismo; danças circulares.

\section{Resumen}

Educar para las relaciones raciales étnicos significa para todos los estudiantes y profesores, independientemente de su etnia, experiencia en África y cultura y la historia de Afro-Brasileño porque sabemos cuánto la invisibilidad de estos interfieren en construcción de representaciones sobre el negro en Brasil. Este estudio propone una acción educativa dirigida hacia el cumplimiento de la Ley 10.639/03, mediante la metodología de las danzas circulares en formación continua de docentes en los valores de la civilización Afro Brasileña tales como: cooperativas, circularidad, alegría, territorialidad, oralidad, religión, ascendencia, memoria y energía vital. Las danzas circulares proporcionan momentos de cooperación, relajación y conocimiento mediante la práctica de los bailes de distintos pueblos. Según los datos narrativos de 10 maestros que han participado en la formación continuada "danzas circulares en la formación de maestros para las relaciones étnica y racial se observó que las cuestiones de racismo y interseccionalidades, intolerancia religiosa y la discriminación son las dudas y tensiones encontradas con frecuencia en el aula. El uso de danzas circulares para argumentar y discutir estos temas fue mirado por los maestros como un aprendizaje a través del movimiento, de la oralidad, el anfitrión de la rueda, es decir, una actividad ligera y alegre donde puede reflexionar, aprender, dimitir y respetar la diversidad étnica y racial.

\footnotetext{
${ }^{1}$ Mestranda do Programa de Pós-Graduação em Educação da FURG. E-mail: giselemarie25@ hotmail.com

${ }^{2}$ Doutora em Educação em Ciências, professora do PPG Educação em Ciências e do PPG Educação da FURG.

E-mail: raquelquadrado@ hotmail.com
} 
Palabras clave: formación continua de los docentes; racismo; danzas circulares.

\begin{abstract}
Educating for ethnic-racial relations means enabling all students and teachers, regardless of their ethnicity and knowledge about Afro-Brazilian history and culture, because we know how much the invisibility of those factors interfere in the construction of black representation in Brazil. This study proposes a pedagogical practice in compliance with the law 10.639/03, using the methodology of circular dances in the continued education of teachers based on the Afro-Brazilian civilizing values, such as: cooperativism, circularity, playfulness, territoriality, orality, religiosity, ancestry, memory and vital energy. Circular dances provide moments of cooperation, relaxation and introspection through the practice of the dances of different peoples. According to the narrative data of 10 teachers who participated in the continued education course "Circular Dances in the education of teachers in the ethnic-racial relations", questions on racism, religious intolerance and discrimination are the most common doubts and stresses faced in the classroom. The use of circular dances to discuss and problematize these themes was considered by teachers as learning through movement, orality, welcoming in the circle, in other words, a light and happy activity, in which is possible to reflect, to know, to reframe and to respect ethnic-racial diversity.
\end{abstract}

Keywords: continued education of teachers, racism, circular dances.

\title{
1. Introdução:
}

Espera-se que ao introduzir nos currículos a discussão sistemática das relações étnicoraciais e da história e cultura africana e afro-brasileiras sejam impulsionadas mudanças significativas na educação brasileira. Com isso articula-se respeito e reconhecimento à diversidade étnico-racial, possibilitando uma educação antirracista e outros olhares para a representatividade do(a) negro(a) em nossa sociedade.

Dentre as metas norteadoras para o cumprimento da lei 10.639/03, lei que estabelece a obrigatoriedade do ensino da história e cultura afro-brasileiras e africanas nas escolas públicas e privadas, do ensino fundamental e médio, a política de programas de formação continuada presencial, semipresencial e a distância de gestores(as) e profissionais da educação está prevista no Plano Nacional de Implementação das Diretrizes Curriculares Nacionais para a educação das Relações Étnico-raciais e para o Ensino de História e Cultura Afro-Brasileira e Africana. (BRASIL, 2013).

Formação continuada de professores(as) é "toda a intervenção que provoca mudanças no comportamento, na informação, nos conhecimentos, na compreensão e nas atitudes dos professores em exercício". (IMBERNÓN, 2010, p. 115)

Observa-se que muitos foram os avanços na produção de conhecimento sobre a formação continuada de professores(as) no século passado, porém estas não são mais suficientes para acompanhar as mudanças e resolver as questões sociais, políticas, profissionais, educacionais de professores(as) e alunos(as) do século XXI.

Nos processos de formação continuada é importante fortalecer o desenvolvimento de atitudes de cooperação e de solidariedade, bem como entender que sem a participação dos(as) 
professores(as), qualquer processo de formação poderá se tornar uma ficção. Na formação devemos trabalhar com os(as) professores(as) e não sobre eles(as).

As mudanças no meio social e político contribuíram para outra forma de perceber a função docente, o que possibilitou que a formação fosse além de uma mera atualização profissional, ou seja, criou "espaços de reflexão e participação nos quais o profissional da educação faz surgir a teoria subjacente a sua prática com o objetivo de recompô-la, justificá-la ou destruí-la”. (IMBERNÓN, 2010, p.118)

Diante do que foi exposto sobre a formação docente, sua função e seu potencial, fazemos algumas considerações sobre como está a formação docente em relação à educação para as relações étnico-raciais.

Segundo Gomes (2003), a articulação entre as questões da diversidade étnico/cultural e formação docente, apesar de terem surgido algumas iniciativas de inserção desta temática, ainda não é privilegiada nos estudos que discutem o trabalho docente no Brasil.

Entendemos que a lacuna nos currículos escolares sobre a temática étnico-racial, tem acarretado prejuízos à formação, tanto dos(as) alunos(as) como dos(as) professores(as).

O professor em qualquer fase de seu processo de formação, bem como de sua vivência pessoal, é um sujeito cultural e social, que como tal recebe efeitos positivos e negativos da configuração histórica, social e econômica da sociedade, que no caso do Brasil é extremamente pautada sobre estereótipos inferiorizantes, preconceitos e discriminações acerca de alguns grupos ditos "minoritários", construídos historicamente e que são pautados pelas relações de poder. (ALVES; BACKER, 2013, p. 2)

Gomes, sobre a relação entre as questões étnico-raciais e a formação de professores(as), diz que "é fato que nem a escola nem os centros de formação de professores 'inventaram', sozinhos, os diversos preconceitos e estereótipos. Isso não os isenta, porém, da necessidade de assumirem um posicionamento contra toda e qualquer forma de discriminação". (2003, p.160)

Assim, entendemos que existe uma relação direta entre a formação docente e a inserção desta temática nos currículos escolares e no dia a dia da escola. E ao compreender essa relação, vislumbramos uma possibilidade de viabilizar a inserção desta temática por meio das danças circulares.

Conforme, Giraflor:

As danças circulares são desenvolvidas visando ampliar o conhecimento em direção ao bem-estar físico, mental, emocional, energético e social. Inúmeros ritmos, cantos e danças, de povos e culturas do mundo são vivenciados. Em meio a momentos de 
muita descontração e também, a momentos de introspecção, a pessoa que está na roda se percebe como um ser humano íntegro e amoroso. (2013, p.11)

A principal referência que temos das Danças Circulares é Bernhard Wosien (19081986), bailarino alemão, coreógrafo e professor de danças. Bernhard interessou-se em pesquisar as danças em várias comunidades desde 1952. A percepção do professor era de que a dança folclórica tradicional estava começando a mudar e suas raízes estavam sendo esquecidas. O desejo de Wosien era resgatar o sentido da dança, ou seja, dançar junto, jovens e velhos(as), celebrando um nascimento ou casamento, pedindo chuva para as plantações ou agradecendo uma boa colheita e etc. Em 1976, Bernhard Wosien foi convidado a ensinar as danças na fundação Findhorn onde elas se tornaram parte integrante do dia a dia desta comunidade. Findhorn realiza cursos voltados ao desenvolvimento humano e está localizada ao norte da Escócia. (BARTON, 2012)

As danças circulares que hoje praticamos celebram o dançar juntos no círculo, de mãos dadas em busca de um ritmo e de uma harmonia comuns, resgatando relações e vivenciando valores éticos de convivência cooperativa através das músicas e das danças de diferentes povos.

Dançamos, geralmente de mãos dadas, às vezes, mãos soltas, em duplas ou trios. Desenhamos no chão, formas variadas, círculos em movimentos de abrir e fechar, espirais e linhas. Os gestos completam a expressão criativa individual e coletiva das diversas culturas.

A dança aplicada pedagogicamente para Wosien, proporciona:

[...] o desenvolvimento do movimento, do espaço de execução do movimento, do ritmo, da ordem, da expressão, da música e do movimento, da referência espacial, da referência do eu e do parceiro, da referência de comunidade, num plano mais elevado do ser. (2000, p.65)

Dançar as danças de diversas etnias, resgatando a diversidade cultural aponta, talvez, uma forma coletiva de aprendizagem de si, $\operatorname{dos}($ as) outros(as) e das diferenças.

Na prática da dança circular é possível identificar princípios civilizatórios africanos, como: circularidade, respeito, oralidade, religiosidade, corporeidade, musicalidade, cooperativismo, territorialidade, ancestralidade, memória, ludicidade e energia vital. (TRINDADE, 2010).

Garantir o direito à educação sobre a história e cultura africana e afro-brasileira nos espaços escolares, poderá contribuir na diminuição do preconceito em relação aos negros(as), bem como ajudar na afirmação de crianças, adolescentes, jovens, adultos(as), professores(as) 
e outros(as) profissionais negros(as) através do resgate da memória de sua história. A construção de uma identidade racial envolve conhecer as questões históricas, culturais e sociais, além das questões subjetivas, ou seja, entender como é ser negro no Brasil.

Se o(a) professor(a) não recebeu em sua formação orientação pedagógica sobre as relações étnico-raciais, possivelmente não se sentirá capacitado(a) para abordar as questões raciais em sala de aula ou em outro ambiente escolar. Não se sentirá capacitado(a) para intervir e enfrentar situações e comportamentos racistas, discriminatórios e/ou estereotipados. E o que geralmente acontece é que o professor ou a professora, seja por omissão ou seja por declarações racistas, seja pelo fato de não considerar a questão racial como relevante ou existente, atua difundindo e mantendo o preconceito e a discriminação raciais na sala aula.

O que é Racismo? Qual é a origem do Racismo? Qual é a diferença entre racismo, discriminação e preconceito?

$\mathrm{O}(\mathrm{A})$ professor(a), na sala de aula, precisa ser conhecedor(a) de todas estas questões para poder exercer uma educação antirracista na escola e na vida.

Para falar sobre estes conceitos, iremos dialogar com Antônio Santa'nna. De acordo com autor, a prática da discriminação racial começou na Europa no século XV. Antes, na Idade Média, a discriminação baseava-se nas questões religiosas, políticas, e etc., não em diferenças biológicas ou raciais como acontece hoje.

O racismo talvez seja-a pior forma de discriminação, porque o discriminado não pode mudar suas características raciais.

O racismo, como ideologia elaborada, é fruto da ciência européia a serviço da dominação sobre a América, Ásia e África. A ideologia racista se manifesta a partir do tráfico escravo, mas adquire o status de teoria após a revolução industrial européia. Aimé Césaire, em seu Discurso sobre o Colonianismo, escrito no imediato do pós-guerra, salienta que Cortez e Pizarro pilhavam e matavam na conquista da América[...] (PEREIRA, 1978, p.39)

Desde o século $\mathrm{XV}$, muitas páginas em tratados, ensaios, monografias, teses, etc., foram escritas para sustentar o insustentável: o racismo como uma prática necessária e justificável.

Aristóteles (apud Sant'ana) dizia que

[...] uma parte dos homens nasceu forte e, resistente, destinada expressamente pela natureza para o trabalho duro e forçado. A outra parte - os senhores, nasceu fisicamente débil; contudo, possuidora de dotes artísticos, capacitada, assim, para fazer grandes progressos nas ciências filosóficas e outras. (2005, p. 43) 
Este discurso de Aristóteles serviu para justificar a escravidão de negros(as) e indígenas. Já as bases do racismo moderno estão na Idade Média através de intelectuais ligados(as) à Igreja Católica Romana a respeito da superioridade, de uma raça sobre a outra.

Sobre o conceito de preconceito, o autor diz:

Preconceito é uma opinião preestabelecida, que é imposta pelo meio, época e educação. Ele regula as relações de uma pessoa com a sociedade. Ao regular, ele permeia toda a sociedade, tornando-se uma espécie de mediador de todas as relações humanas. Ele pode ser definido, também, como uma indisposição, um julgamento prévio, negativo, que se faz de pessoas estigmatizadas por estereótipos. (SANT'ANA, 2005, p.62)

Os preconceitos, como por exemplo: "toda a criança negra vai mal na escola", "o negro é burro", entre outros, transformam-se em posições diante da vida, ou seja, atos que diferenciam, excluem e restringem uma pessoa ou um grupo de pessoas por causa da sua cor ou raça e ao serem empregados nas relações interpessoais, carregam consigo outras categorias como: os estereótipos, a discriminação e o racismo. (SANT’ANA, 2005)

Conforme o decreto $n^{\circ} 65.810 / 69$

[...] a expressão "discriminação racial", significa qualquer distinção, exclusão, restrição ou preferências baseadas em raça, cor, descendência ou origem nacional ou étnica, que tenha como objeto ou efeito anular ou restringir o reconhecimento, o gozo ou exercício, em condições de igualdade, os direitos humanos e liberdades fundamentais no domínio político, social ou cultural, ou em qualquer outro domínio da vida pública. (BRASIL, 1969)

Segundo Lopes,

o combate ao racismo, ao preconceito e à discriminação, em nível escolar, deve tomar as mais diferentes formas de valorização da pessoa humana, povos e nações, valorização que se alcança quando descobrimos que as pessoas, mesmo com suas dessemelhanças, ainda são iguais entre si e iguais a nós, com direito de acesso aos bens e serviços de que a sociedade dispõe, de usufrui-los, criar outros, bem como de exercer seus deveres em benefício próprio e dos demais. (2005, p.187)

Somos diferentes, mas iguais no direito e no acesso a bens e serviços, ao conhecimento da história e cultura dos/as nossos/as antepassados/as. Temos direito a seguir as crenças das diversas religiões que estão presentes no território brasileiro, pois de acordo com a Constituição, o Brasil é um Estado laico.

Mas, infelizmente a intolerância religiosa existe e sua prática não é recente. 
Conforme Silva e Soares, "[...]a história da humanidade é marcada por disputas de território e poder que resultam na supremacia das manifestações culturais e religiosas do conquistador frente à submissão social, econômica e política dos oprimidos”. (2015, p.5)

De acordo com estas autoras, o fato da intolerância religiosa ser praticada, geralmente, contra as religiões de matriz africana, está relacionado intrinsecamente ao preconceito racial, declarado aos/as negros/as, desde a escravidão no Brasil. (COSTA, 2012)

A superiodade do(a) branco(a), assim como a inferioridade do(a) negro(a), foram criadas, inventadas. Conforme o autor, a origem do menosprezo e inferioridade de tudo que vem do(a) negro(a) estaria na criação do conceito de superiodade do(a) branco(a).

A imposição da superioridade da raça branca, ou seja, a valorização da sua cultura, sua crença, seus ritos construíram no imaginário coletivo sentimentos de desprezo, preconceito, ódio e violência contra a população negra, e isso se perpetua até os dias de hoje.

De acordo com o artigo $18^{\circ}$ do decreto $n^{\circ} 592 / 92$, referente ao pacto internacional sobre os direitos civis e políticos:

Toda pessoa terá direito a liberdade de pensamento, de consciência e de religião. Esse direito implicará a liberdade de ter ou adotar uma religião ou uma crença de sua escolha e a liberdade de professar sua religião ou crença, individual ou coletivamente, tanto pública como privadamente, por meio do culto, da celebração de ritos, de práticas e do ensino. Ninguém poderá ser submetido a medidas coercitivas que possam restringir sua liberdade de ter ou de adotar uma religião ou crença de sua escolha. A liberdade de manifestar a própria religião ou crença estará sujeita apenas à limitações previstas em lei e que se façam necessárias para proteger a segurança, a ordem, a saúde ou a moral públicas ou os direitos e as liberdades das demais pessoas. Os Estados Partes do presente Pacto comprometem-se a respeitar a liberdade dos pais e, quando for o caso, dos tutores legais - de assegurar a educação religiosa e moral dos filhos que esteja de acordo com suas próprias convicções. (BRASIL, 1992).

Apesar dos dispositivos legais vigentes como as leis: 7.716/89, 10.639/03, 10.678/03 e outros, percebemos que a falta de compreensão sobre o que é o racismo, seus desdobramentos e interseccionalidades por parte da maioria dos/as docentes pode, no ambiente escolar, perpetuar práticas racistas, discriminatórias e de intolerância religiosa, seja por omissão ou participação.

\section{Metodologia}

Para a produção dos dados desta pesquisa qualitativa foi realizado um curso de formação continuada para professores(as), das redes estadual, municipal e federal de ensino, sobre educação étnico-racial com a metodologia das danças circulares. Os(as) participantes receberam um caderno para suas narrativas docentes, com objetivo de registrarem suas 
reflexões, opiniões, sugestões, experiências e críticas sobre os temas trabalhados em cada módulo. Durante os encontros do curso, algumas questões eram lançadas com o intuito de desencadear a escrita das narrativas.

O Curso foi oferecido pela Assessoria de Relações Étnicas da $18^{\mathrm{a}}$ Coordenadoria Regional de Educação (CRE), da qual eu sou responsável, com duração de 40 horas (16 presenciais e 24 à distância).

A parte presencial do curso foi organizada em 4 módulos. Cada participante recebeu um material pedagógico produzido pela pesquisadora, contendo:- 1 Sacola; 1 CadernoNarrativas Docentes; 1 Apostila contendo o roteiro correspondente a cada Módulo, bem como o tema a ser desenvolvido, os objetivos, a descrição das coreografias das danças circulares (origem, música entre outros), indicação de leituras complementares e filmes; 1 Centrinho de roda (Adorno que serve de referência para os participantes da roda de dança circular) ; 1 Baralho Adinkra (cartas com os símbolos adinkras, os quais constituem um sistema de escrita que preserva e transmite valores fundamentais, criados pelos povos Alan, presentes nos países de Gana, Costa do Marfim e Togo); um CD e 1 DVD (foram entregues ao final do curso com todas as músicas e coreografias).

A análise dos dados, para este estudo, deu-se a partir das dúvidas e tensões que a maioria dos(as) professores(as) enfrentam em sala de aula. Nas escritas das narrativas, os assuntos como racismo, preconceito, discriminação e a intolerância religiosa foram apontados como os que mais causaram polêmicas, desconforto e/ou despreparo na sala de aula. Sendo assim, selecionamos para análise as três questões que abordaram estes temas e suas respectivas escritas narrativas, são elas:

Questão 1 do Encontro I: Quais são as dúvidas e tensões que vocês, docentes, enfrentam na sala de aula sobre as temáticas das relações étnico-raciais (racismo, discriminação, intolerância religiosa entre outros)?

Questão 1 do Encontro II: Como você percebeu a abordagem do tema tão complexo, como a intolerância religiosa, a partir das danças circulares?

Questão 2 do Encontro III: O racismo pode ser abordado através das danças circulares de forma lúdica sem que se perca a seriedade das questões que envolvem este tema?

\section{Resultados}

Nas respostas obtidas na questão 1 do Encontro I: Quais são as dúvidas e tensões que vocês, docentes, enfrentam na sala de aula sobre as temáticas das relações étnico-raciais (racismo, discriminação, intolerância religiosa entre outros)?, encontramos a discriminação 
citada em $80 \%$, das respostas, a intolerância religiosa em $60 \%$ das narrativas e o racismo em $40 \%$.

As narrativas apontaram para as seguintes percepções docentes:

- falta de leitura sobre as temáticas, não reconhecer-se racista na fala e no comportamento, o entendimento de sempre estar despreparado(a) para discutir assuntos polêmicos, negação do diálogo, proibição de gestos e movimentos corporais, intolerância religiosa e discriminação entre alunos(a) e principalmente entre docentes, saber diferenciar os conceitos: racismo, preconceito e discriminação, dificuldade em romper com a lógica eurocêntrica de uma visão estereotipada das religiões de matriz africana.

De acordo com Munanga, alguns professores e educadores não receberam na sua formação a necessária preparação para lidar com os desafios de conviver com a diversidade e as manifestações de discriminação que resultam dela diariamente. Essa falta de preparo, pode ser considerada efeito do mito da democracia racial, pois ao encobrir os conflitos raciais, encobriu-se também as desigualdades, as práticas de racismo, discriminação e preconceito.

O autor lembra que somos produtos de uma educação eurocêntrica e que podemos reproduzir consciente ou inconscientemente os preconceitos presentes em nossa sociedade.

\begin{abstract}
Partindo da tomada de consciência dessa realidade, sabemos que nossos instrumentos de trabalho na escola e na sala de aula, isto é, os livros e outros materiais didáticos visuais e audiovisuais carregam os mesmo conteúdos viciados, depreciativos e preconceituoso em relação aos povos e culturas não oriundos do mundo ocidental. Os mesmos preconceitos permeiam também o cotidiano das relações sociais de alunos entre si e de alunos com professores no espaço escolar. No entanto, alguns professores, por falta de preparo ou por preconceitos neles introjetados, não sabem lançar mão das situações flagrantes de discriminação no espaço escolar e na sala como momento pedagógico privilegiado para discutir a diversidade e conscientizar seus alunos sobre a importância e a riqueza que ela traz à nossa cultura e à nossa identidade nacional. (2005, p.15)
\end{abstract}

Reconhecer o Brasil como um país racista e superar o mito da democracia racial são passos importantes para uma educação antirracista nas escolas:

cremos que a educação é capaz de oferecer tanto aos jovens como aos adultos a possibilidade de questionar e desconstruir os mitos de superioridade e inferioridade entre grupos humanos que foram introjetados neles pela cultura racista na qual foram socializados. Apesar da complexidade da luta contra o racismo, que conseqüentemente exige várias frentes de batalhas, não temos dúvida de que a transformação de nossas cabeças de professores é uma tarefa preliminar importantíssima. (p.17) 
O preconceito contra as religiões de matriz africana, conforme Silva e Soares, está "intrinsecamente relacionado ao preconceito racial, contra o negro desde os navios negreiros" (2015, p.3).

Com a abolição da escravatura,

\begin{abstract}
“o negro foi abandonado a sua própria sorte, vivendo numa situação de extremo pauperismo, aglomerando-se em bairros pobres, em habitações em estado de total miserabilidade, trabalhando (quando conseguiam) em subempregos, [...], levando uma vida social de desagregação familiar, alcoolismo e abandono.(p.3).
\end{abstract}

Assim as manifestações culturais e religiosas da população negra no Brasil, ficaram ainda mais marginalizadas e discriminadas.

Na questão 1 do Encontro II: Como você percebeu a abordagem do tema tão complexo, como a intolerância religiosa, a partir das danças circulares?, emergiram algumas narrativas:

-Sujeito 3: "vi nas danças circulares uma potencialidade de desmistificar preconceitos e intolerâncias a respeito da religião afro";

-Sujeito 4: "percebi a conexão que podemos fazer entre a dança, a música e a reflexão sobre o verdadeiro conhecimento da cultura de religiões tão perseguidas por erros da escrita da história eurocêntrica; na medida de resgatar a origem africana de resgatar a origem africana através de ritmos";

-Sujeito 5: "fiquei muito encantada com a abordagem feita antes de debatermos o tema, especialmente quando foram confrontados, através de imagens dos Deuses gregos e os Deuses Africanos. Para a sala de aula, achei um recurso muito interessante. A partir dessa problematização o debate fluiu até chegarmos ao sincretismo religioso. Quando partimos para a dança, fizemos com alegria e leveza";

Sujeito 6: "as danças circulares possibilitam a proximidade entre os diferentes favorecendo a sensibilidade e encorajamento para expressar a opinião mesmo que divergente sobre a religiosidade de matriz africana";

-Sujeito 7: "Achei a abordagem perfeita por que nos fez refletir e a mim ajudará na abordagem que também faço enquanto professora";

-Sujeito 8: "gostei muito do tema e da oportunidade de aprender, mas gostaria de uma maior participação das escolas. É um assunto tão importante, mas que acaba por ter um número mínimo de pessoas interessadas e a dificuldade de levar para escolas o debate e aceitação por parte do corpo docente". 
Entende-se que o espaço da escola é um espaço social importante na vida dos sujeitos, dessa forma, o tema religioso deveria ser abordado na sala de aula, levando-se em consideração sua complexidade e diversidade. De acordo com Sinisterra, "o papel do professor seria de facilitar uma maior compreensão do fenômeno religioso em suas perspectivas cultural e não de se sentir responsável pelo desenvolvimento de processos doutrinários e de vinculação a um determinado sistema de crenças”. (2006, p.57)

Conhecer e compartilhar conhecimentos sobre a cultura afro-brasileira e africana pode ser uma excelente oportunidade pedagógica para desmistificar ideias preconceituosas sobre os negros e negras, principalmente dos praticantes de religiões de matriz africana. "Da mitologia grega todo mundo sabe um pouco, mas da mitologia africana, nada”. (OLIVEIRA, 2006, p.48) É preciso criar estratégias para contar essa história.

As danças circulares na educação demostrou ser uma potente ferramenta pedagógica, para introduzir, entre outros, o tema sobre religiosidade e da intolerância religiosa, pois ao dançar as danças de diversos ritmos afro-brasileiros, resgatamos a diversidade cultural revelando, talvez, uma forma coletiva de aprendizagem de si, dos(as) outros(as) e das diferenças.

$\mathrm{Na}$ prática da dança circular é possível identificar princípios civilizatórios afro-brasileiros como: circularidade, respeito, oralidade, religiosidade, corporeidade, musicalidade, cooperativismo, territorialidade, ancestralidade, memória, ludicidade e energia vital. (TRINDADE, 2010)

As danças circulares celebram o dançar juntos no círculo, de mãos dadas em busca de um ritmo e de uma harmonia comuns, resgatando relações e vivenciando valores éticos de convivência cooperativa através das músicas e das danças de diferentes povos.

A dança aplicada pedagogicamente para Wosien, proporciona:

O desenvolvimento do movimento, do espaço de execução do movimento, do ritmo, da ordem, da expressão, da música e do movimento, da referência espacial, da referência do eu e do parceiro, da referência de comunidade, num plano mais elevado do ser. (2000, p. 65)

De acordo com Gomes,

é necessário que, na educação, a discussão teórica e conceptual sobre a questão racial esteja acompanhada da adoção de práticas concretas. Julgo que seria interessante se pudéssemos construir experiências de formação em que os professores pudessem vivenciar, analisar e propor estratégias de intervenção que 
tenham a valorização da cultura negra e a eliminação de práticas racistas como foco principal. Dessa forma, o entendimento dos conceitos estaria associado às experiências concretas, possibilitando uma mudança de valores. Por isso, o contato com a comunidade negra, com os grupos culturais e religiosos que estão ao nosso redor é importante, pois uma coisa é dizer, de longe, que se respeita o outro, e outra coisa é mostrar esse respeito na convivência humana, é estar cara a cara com os limites que o outro me impõe, é saber relacionar, negociar, resolver conflitos, mudar valores.(2005, p.149)

Na questão 2 do Encontro III: O racismo pode ser abordado através das danças circulares de forma lúdica sem que se perca a seriedade das questões que envolvem este tema? -Sujeito 1: “desde o primeiro encontro percebo o quanto as danças circulares está presente em nossos registros. Escutar músicas, sons diversos, nos remete ao conhecimento do aprender com o movimento e escuta. Trocando ideias, desvendando histórias, o acolhimento da roda nos leva a reflexão da verdadeira contribuição e benefícios que nos trouxeram e deixaram nossos antepassados que foram retirados da África";

-Sujeito 2: "Sim acredito que racismo pode ser abordado com o uso das danças circulares, primeiro ouvindo as músicas e pedindo que cada um diga o que entendeu, por que em um grupo a mesma coisa ouvida é interpretada de maneiras diferentes e isso dá uma boa conversa e depois por em prática a dança; Sempre vai ter os mais relutantes, principalmente os meninos, tem que ir aos poucos para conquistar todos";

-Sujeito 3: "Com certeza, cantar e dançar é um ato politico. Nosso corpo e nossos gestos são nossa resistência. Quando dançamos nos libertamos nos unimos, ficamos fortes;

-Sujeito 4: "Tranquilamente percebo que possamos abordar o racismo de forma lúdica sem perder a seriedade, pois brincando parece-me uma via sensível de reflexão";

-Sujeito 5: "Com certeza. É uma maneira "leve" de tratar essas questões e também atrativa, pois, a dança e a música podem tornar esse tema menos engessado e também repleto de préconceitos";

-Sujeito 6: "Sobre a pertinência das danças circulares na abordagem de questões que envolvem o racismo, com certeza acredito que é um ótimo instrumento para se ampliar os conhecimentos acerca das contribuições históricas e culturais que o povo africano nos trouxe, como também pode ser a dança, instrumento de ruptura com ideias equivocadas e preconceituosas";

-Sujeito 7: “As danças circulares fazem parte da cultura afro, e possibilitam, trabalhar as questões raciais exaltando a origem das danças africanas, para que se rompa com os preconceitos sobre as tradições culturais do povo negro"; 
-Sujeito 9:" Sim, com certeza, desde que seja bem conversada antes dizendo a origem, grandeza e significado para os povos negros e sociedade em geral".

A simbologia do círculo, de acordo com Ostetto (2009), evoca equilíbrio, totalidade, integração de diferenças e solidariedade. A autora nos convida a pensar sobre uma prática educativa através da imagem de uma roda, círculo e/ou mandala. Uma ação educativa inspirada na circularidade, ou seja, utilizar o círculo como princípio, aquele que inclui tudo e todos (as).

De acordo com Ostetto:

Pensar circularmente significaria não pensar em linha reta, na afirmação da verdade, da única voz, do conhecimento absoluto. Significaria abrir-se ao diálogo, ao acolhimento da dúvida e da diversidade, à construção de múltiplos enredos afirmados no encontro das singularidades de crianças e adultos, de alunos e professores. (2006, p.182)

Através da circularidade, da oralidade, da ludicidade das danças circulares foi possível abordar as diferenças entre o "eu" e o "outro" como algo que nos constitui, que completa e não como algo que nos inferioriza.

Conforme Gomes,

é justamente o campo dos valores que apresenta uma maior complexidade, quando pensamos em estratégias de combate ao racismo e de valorização da população negra na escola brasileira. Tocar no campo dos valores, das identidades, mexe com questões delicadas e subjetivas e nos leva a refletir sobre diversos temas presentes no campo educacional. (2005 p. 149)

\section{Algumas Considerações}

O entendimento sobre o que é racismo, discriminação racial e preconceito, poderia ajudar os(as) educadores(as) a compreenderem a especificidade do racismo brasileiro e auxiliá-los a identificar quando uma prática racista acontece na escola e assim realizar discussões acompanhadas de ações concretas para combate-la. Construir experiências nas formações de professores(as) que proporcionem vivências sobre a valorização da cultura negra e eliminação de práticas racista possibilitaria uma mudança de valores, e "[...]tocar no campo de valores, das identidades, mexe com questões delicadas e subjetivas e nos leva a refletir sobre diversos temas presentes no campo educacional. (GOMES, 2005, p.149)

De acordo com as narrativas dos(as) docentes, neste estudo, observamos que as questões sobre racismo, discriminação, preconceito e intolerância religiosa são as dúvidas e tensões mais frequentes enfrentadas em sala de aula e que devido a ausência da abordagem 
desta temática na formação dos(as) docentes faz com que estes(as) não se sintam capacitados(as) para lidar com assuntos considerados polêmicos no cotidiano escolar.

O número reduzido de professores(as) que participam das formações continuadas sobre esta temática também é indicado pelos(as) participantes como um fator limitador para o comprometimento da escola com uma educação antirracista e de valorização da cultura e história dos negros no Brasil.

A utilização das danças circulares para discutir e problematizar estas temáticas foi considerada pelos(as) docentes como uma ferramenta eficiente que se relaciona com os valores civilizatórios afro-brasileiros e assim através do movimento, da oralidade, do acolhimento da roda, ou seja, uma atividade leve e alegre, é possível refletir, conhecer, ressignificar e respeitar a diversidade étnico-racial.

\section{Referências}

ALVES, Ângela Maria; BACKES, José Licínio. Educar para as relações raciais: um desafio para a formação de professores. $36^{a}$ REUNIÃO NACIONAL DA ANPED - Goiânia / GO Campus Samambaia/UFG - 29/09 a 02/10/2013 GT 2: Educação e identidade/diferença negra.

BARTON, Anna. O que é dança sagrada? In: Renata C. L. Ramos (Org.) Danças Circulares: dançando o caminho sagrado. São Paulo: TRIOM, 2012.

BRASIL. Plano Nacional de Implementação das Diretrizes Curriculares Nacionais para a Educação das Relações Étnico-raciais e para o Ensino de História e Cultura Afro-Brasileira e Africana./ Ministério da Educação, Secretaria de Educação Continuada, Alfabetização, Diversidade e Inclusão. Brasilia: MEC, SECADI, 2013. P.104.

BRASIL. Decreto $n^{\circ}$ 65.810, de 8 de dezembro de 1969. Promulga a Convenção Internacional sobre a Eliminação de todas as Formas de Discriminação Racial. Disponível em: http://legis.senado.gov.br/legislacao/ListaTextoIntegral.action?id=94836. Acesso em 12 out. 2017.

BRASIL. Decreto n592/92. Atos Internacionais. Pacto Internacional sobre Direitos Civis e Políticos. Promulgação. Disponível em: http://www.planalto.gov.br/ccivil_03/decreto/19901994/d0592.htm. Acesso em: 18 out. 2017.

COSTA, Ricardo Cesar Rocha da. O pensamento social brasileiro e a questão racial: da ideologia do "branqueamento" às "divisões perigosas". In: MIRANDA, Claudia et al (Org.). Relações Étnico-Raciais na Escola: desafios teóricos e práticas pedagógicas após a Lei ${ }^{\circ}$ 10.639. Rio de Janeiro: Quartet/FAPERJ, 2012.

GIRAFLOR. Danças Circulares. Apostila XII Edição Curso de Formação, 2013. 
GOMES, Nilma Lino. Trabalho docente, formação de professores e diversidade étnico cultural. In: OLIVEIRA, Dalila Andrade (Org.). Reformas Educacionais na América Latina e os trabalhadores docentes. Belo Horizonte: Autêntica, 2003.

GOMES, Educação e Relações Raciais: Refletindo sobre algumas estratégias de atuação. In: MUNANGA, Kabengele (Org.). Superando o Racismo na escola. 2 ed. Revisada Brasília: Ministério da Educação, Secretaria de Educação Continuada, Alfabetização e Diversidade, 2005, p.143-154.

IMBERNÒN, Francisco. Formação Continuada de Professores. Porto Alegre: Artmed, 2010.

LOPES, Vera Neusa. Racismo. Preconceito e discriminação: Procedimentos didáticopedagógico e a conquista de novos comportamentos. In: MUNANGA, Kabengele (Org.). Superando o Racismo na Escola. 2 ed. Revisada. Brasília Ministério da Educação, Secretaria de Educação Continuada, Alfabetização e Diversidade, 2005.

OLIVEIRA, Kiusam Regina de. Religiosidade de Matriz Africana: Desconstruindo Preconceitos. In BRANDÃO, Ana Paula, TRINDADE, Azoilda Loretto. Modos de brincar: cadernos de atividades, saberes e fazeres. v.5. Rio de Janeiro A cor da cultura, 2010.

OSTETTO, Luciana E. Na dança e na educação: o círculo como princípio. Educação e Pesquisa, São Paulo, v.35, n.1, p. 165-176, jan/abr. 2009

PEREIRA, José Maria Nunes. Colonialismo, Racismo, Descolonização. Revista Estudos Afro-Asiáticos, n. 2, maio/agosto, 1978.

SANT'ANA, Antônio Olímpio de. História e conceitos básicos sobre o racismo e seus derivados. In: Superando o Racismo na escola. MUNANGA, Kabengele (Org.). Superando o Racismo na Escola. 2 ed. Revisada. Brasília: Ministério da Educação, Secretaria de Educação Continuada, Alfabetização e Diversidade, 2005, p.39-67.

SILVA, Lucilia Carvalho da; SOARES, Katia dos Reis Amorim. A Intolerância Religiosa face às religiões de Matriz Africana como expressão das relações étnico-raciais brasileiras: $\mathrm{O}$ terreno do combate à intolerância no Município de Duque de Caxias. Revista EDUC Faculdade de Duque de Caxias. Vol. 1. No 03/jan-jun 2015.

SINISTERRA, Mary Lilia Congolino. Religião, Sociedade e Pedagogia. In BRANDÃO, Ana Paula, TRINDADE, Azoilda Loretto. Caderno de Textos. A Cor da cultura, 2010.

TRINDADE, Azoilda Loretto. Valores Civilizatórios Afro-brasileiros e educação infantil: uma contribuição afro-brasileira. Modos de brincar: caderno de atividades, saberes e fazeres. Rio de Janeiro: Fundação Roberto Marinho, 2010, p.9-12.

WOSIEN, Bernhard. Dança: um caminho para a totalidade. Tradução Maria Leonor Rodenbach, Raphael de Haro Junior. São Paulo: TRIOM, 2000. 